\title{
BMJ Open Role of requests and communication breakdowns in the coordination of teamwork: a video-based observational study of hybrid operating rooms
}

Jonas Ivarsson (D) , ${ }^{1}$ Mikaela Åberg

To cite: Ivarsson J, Åberg M. Role of requests and communication breakdowns in the coordination of teamwork: a video-based observational study of hybrid operating rooms. BMJ Open 2020;10:e035194. doi:10.1136/ bmjopen-2019-035194

- Prepublication history for this paper is available online. To view these files, please visit the journal online (http://dx.doi. org/10.1136/bmjopen-2019035194).

Received 23 October 2019

Revised 27 March 2020 Accepted 24 April 2020
A) Check for updates

(C) Author(s) (or their employer(s)) 2020. Re-use permitted under CC BY-NC. No commercial re-use. See rights and permissions. Published by BMJ.

${ }^{1}$ Department of Applied Information Technology, University of Gothenburg, Goteborg, Sweden

${ }^{2}$ Department of Education, Communication and Learning, University of Gothenburg, Goteborg, Sweden

Correspondence to Dr Jonas Ivarsson; jonas.ivarsson@gu.se

\section{ABSTRACT}

Objectives This study investigated the functional role of 'requests' in the coordination of surgical activities in the operating room (OR). A secondary aim was to describe, closely, instances of potential miscommunication to scrutinise how so-called conversational repairs were used to address and prevent mistakes.

Design Non-participant video-based observations. Setting Team coordination around image acquisitions (digital subtraction angiography) done during endovascular aortic repair (EVAR) procedures in a hybrid OR.

Methods The study followed and documented a total of 72 EVAR procedures, out of which 12 were video-recorded (58hours). The results were based on 12 teams operating during these recorded surgeries and specifically targeted all sequences involving controlled apnoea. In total, 115 sequences were analysed within the theoretical framework of conversation analysis.

Results The results indicated a simple structure of communication that can enable the successful coordination of work between different team members. Central to this analysis was the distinction between immediate requests and pre-requests. The results also showed how conversational repairs became key in establishing joint understanding and, therefore, how they can function as crucial resources in safety management operations.

Conclusion The results suggest the possibility of devising an interactional framework to minimise problems with communication, thereby enabling the advancement of patient safety. By making the distinction between different types of requests explicit, certain ambiguities can be mitigated and some misunderstandings avoided. One way to accomplish this practically would be to tie various actions to clearer and more distinct forms of expression.

\section{INTRODUCTION}

Previous observational studies on communication and teamwork in the operating room (OR) have identified communication problems that negatively can impact patient safety. ${ }^{1-5}$ Effective communication is crucial in the coordination of interdisciplinary teams and for preventing medical errors. ${ }^{6}$ Based on these findings, improvements in team
Strengths and limitations of this study

All observations are based on detailed analyses of interactions, which video records made possible.

- Based on non-participant observations, the analyses targeted the two conversational phenomena of requests and repairs.

- The study suggests that specific additions be made to current communication models to support more effective communication in medical settings.

- The study was limited to 58 hours of video-recorded interaction.

communication could help advance patient safety. ${ }^{7-10}$

The WHO's Surgical Safety Checklist has been introduced as one initiative to improve communication in the OR. In addition, proposals have been presented for communication models that could be used as more generic templates for effective communication. ${ }^{11} 12$ To reduce miscommunication risks, several researchers and practitioners have focused on so-called closed-loop communication as standardised directives for communication. ${ }^{13-15}$ As described by Parush et al ${ }^{16}$ 'In the closed loop, there was always a sender and a receiver responding in a relevant manner to the conveyed information' ( $\mathrm{p} 481$ ).

By drawing on the concepts of information, senders and receivers, these studies build on early information theories from the 1940s and 1950s that were formulated in the languages of mathematics and engineering. ${ }^{17} 18$ These theories focused on issues related to telephone wires' carrying capacity, but they contained no obvious social components. ${ }^{19}$ Thus, an explanation of why communication can fail falls centrally on the concept of noise, that is, when interference impedes a signal. ${ }^{17}$ To this effect, it also has been shown that noise in the OR may distract surgical team members and affect communication negatively. ${ }^{20}{ }^{21}$ Even 
more specifically, it has been shown that surgeons had to repeat requests (eg, for surgical instruments) five times as often when music was playing in the OR. ${ }^{22}$ However, this latter study also highlights the mechanisms that can be used to compensate for communication problemssocial mechanisms that classical information theories did not cover. Therefore, an alternative for studying communication modelled on senders and receivers is to analyse how (mis)communication is both produced and managed in the course of ongoing talk. ${ }^{23}$

Studies that aim to do this often rely on video-recorded materials from the OR in combination with a conversation analytic approach. The latter is an analytic undertaking concerned with a general understanding of talk and interaction that studies the in situ organisation of talk at a very detailed level. ${ }^{24}$ This is accomplished by working with collections of audio-recorded or videorecorded fragments of talk and action. Such an analytic enterprise can shed light on how and why communication problems occur in the first place, as well as how such problems could be prevented to raise care-work quality. ${ }^{25}$

Within the framework of conversation analysis, the interactional management of communication problems has been analysed and empirically described under the heading of conversational repairs. ${ }^{26-28}$ Repairs are aspects of talk concerned with correcting some communication problem that may be grounded in difficulties with speaking, hearing or understanding. A person can correct a problem with his or her speech (self-repair) or initiate a correction of a problem in another person's speech (other-repair). ${ }^{29} 30$ This kind of analysis departs from the findings that participants involved in interaction constantly display how they understand each other. Based on these displays, participants also can identify breakdowns in intersubjectivity and find the means to repair them. ${ }^{31}$ By analysing such repairs, the analyst can access what participants themselves identify as problematic.

In this tradition, video-based studies on surgery have described practices through which surgeons and other team members coordinate their actions and build a shared understanding of ongoing procedures. ${ }^{23}{ }^{32-34}$ One thing that these studies underscore is the importance of requests or directives for the orderly flow of operations. ${ }^{35}$

Mondada $^{27}$ distinguishes between explicit requests in the form of verbal directives, followed by requested actions and more implicit forms. In the latter case, teamwork can be performed tacitly without explicit requests, in which certain actions are recognised as awaiting a specific response ${ }^{36}$ This is made possible by close monitoring of the surgeon's bodily conduct, coupled with an awareness of the ongoing procedure and its relevant subsequent actions. ${ }^{37}$ In this respect, some surgical practices-such as robotic-assisted surgery, in which the surgeon is separated physically from the rest of the team-become more challenging. ${ }^{10}$ Not only are requests more difficult to hear over greater distances but there also may be problems in monitoring the readiness of the request's recipient. ${ }^{38}$
In ordinary conversations, participants have been shown to be attentive to the contingencies involved in fulfilling a request, and if potential problems are detected, an immediate request may be preceded by something called a prerequest. ${ }^{29}$ These procedures for checking on the other party's availability have not received the same attention in studies on communication in the OR. Building on this understanding, the study, therefore, aimed to investigate how requests (immediate and pre-requests) help organise the coordination of interprofessional communication in the OR. A secondary aim was to describe, closely, instances of potential miscommunication to scrutinise how repairs are used to address and prevent mistakes.

\section{METHODS \\ Research setting}

The materials for this study were collected as part of a larger project focusing on interprofessional communication and the utilisation of medical imaging technologies in a hybrid OR at a Swedish hospital. This project documented all occurrences of a single type of procedure, endovascular aortic repair (EVAR), over an 18-month duration.

This study focused on the coordination of two interdependent actions by separate parties in the OR. The central action here, as part of the medical procedure, is image acquisition using digital subtraction angiography (DSA) during EVAR. DSA combines an imaging process with the concurrent injection of a contrast agent, but for purposes of this analysis, it has been treated as a single unit.

For this imaging process to result in high-quality images, any chest motions caused by respiration must be suppressed. As patients are sedated during this procedure, this task is the anaesthetic nurse's (AN's) responsibility. Respiration is withheld by controlling the respirator, and apnoea is induced temporarily. This second subsidiary action (controlled apnoea) is a prerequisite for a successful DSA.

\section{Data collection}

During an 18-month period, a total of 72 EVAR procedures were carried out in the targeted hybrid OR, of which 12 were selected randomly to be recorded on video. Altogether, 58 hours were recorded with the aid of a ceiling-mounted camera in the OR and by capturing the surgical team's screen.

In relation to observational studies, there is generally a concern for the so-called Hawthorne effect. This observer effect as described by Landsberger ${ }^{39}$ pointed to increased productivity, given the changed circumstances of being observed by outside parties. For the current study, nonparticipant researchers videotaping the activity could reasonably be hypothesised as producing a similar effect. In relation to the aims of the study then, 'productivity' would have to be translated into something akin to 'safe' 
or 'more effective' communication. Did the communication become more successful and less prone to errors because of the study? This issue was not controlled for. However, the study takes an interest in the variation and differences produced within the observed instances. In these observations, the very same teams were to produce both functional and less functional communicative patterns. Understanding the principles that govern this internal variation can be achieved without controlling for the Hawthorne effect.

The total number of image acquisitions (DSA or DynaCT) in the materials was 670 , yielding a mean of 9.3 acquisitions of sequences per procedure (2.17 aq/hour). For the video-recorded subset, the total was 142 , with a mean of 11.8 per procedure (2.65 aq/hour). The mean procedure duration was 4.35 hours.

\section{Patient and public involvement}

Patients were not targeted in any way for the research project and, therefore, were not involved in the research process.

\section{DATA ANALYSIS}

The video materials were edited and processed with Final Cut Pro X (Apple) software. In relation to the study's aims, all video materials were scrutinised, and 115 sequences of controlled apnoea were identified. These sequences subsequently were transcribed using ELAN language-archive software. Following methods outlined by Jefferson, ${ }^{40}$ the data were presented as 'fragments' of actual conversations. In the transcripts, underlined utterances indicate that the speaker is emphasising the talk. CAPS indicate that the speech was delivered at increased volume, while $\mathrm{a}^{\text {' }}{ }^{\prime}$ indicates a rising pitch. Pauses longer than $0.2 \mathrm{~s}$ are represented by their length placed inside parentheses, and micropauses, that is, those shorter than $0.2 \mathrm{~s}$, are represented by a (.).
Multiple project members analysed communication between team members in all 115 sequences involving controlled apnoea, employing conversation analysis. ${ }^{41}$ The analyses specifically targeted the two conversational phenomena of requests and repairs, respectively. This detailed transcription form indicates how interactions are organised in a turn-by-turn fashion. To the unfamiliar reader, such analyses may appear as narrative and descriptive, especially because the technical vocabulary often directly corresponds to ordinary language use. However, Schegloff, ${ }^{24}$ a founding member of this analytical tradition, describes this mode of analysis as being concerned with the understanding of interaction in general:

In one form which data analysis takes in this enterprise, the effort is to elucidate and describe the structure of a coherent, naturally bounded phenomenon or domain of phenomena in interaction, how it is organised and the practices by which it is produced. For this, one ordinarily works with a collection of fragments of talk (or other conduct) which instantiate the phenomenon and its variants (p101).

Thus, this approach operates on the microscopic level of human action, in which the analysis is made possible by the documented details that video records provide. ${ }^{25}$

\section{RESULTS}

As evidenced by the video recordings, most of the apnoea sequences involved the successful coordination of action. However, several minor communication problems also were identified. Out of the 115 sequences, all involved requests in one form or another, while conversational repairs occurred 13 times $(11 \%)$ in relation to the initial phase (onset of apnoea).

A schematised model of the studied communication is represented by the action flowchart depicted in figure 1 . While this representation is clear and simple, many

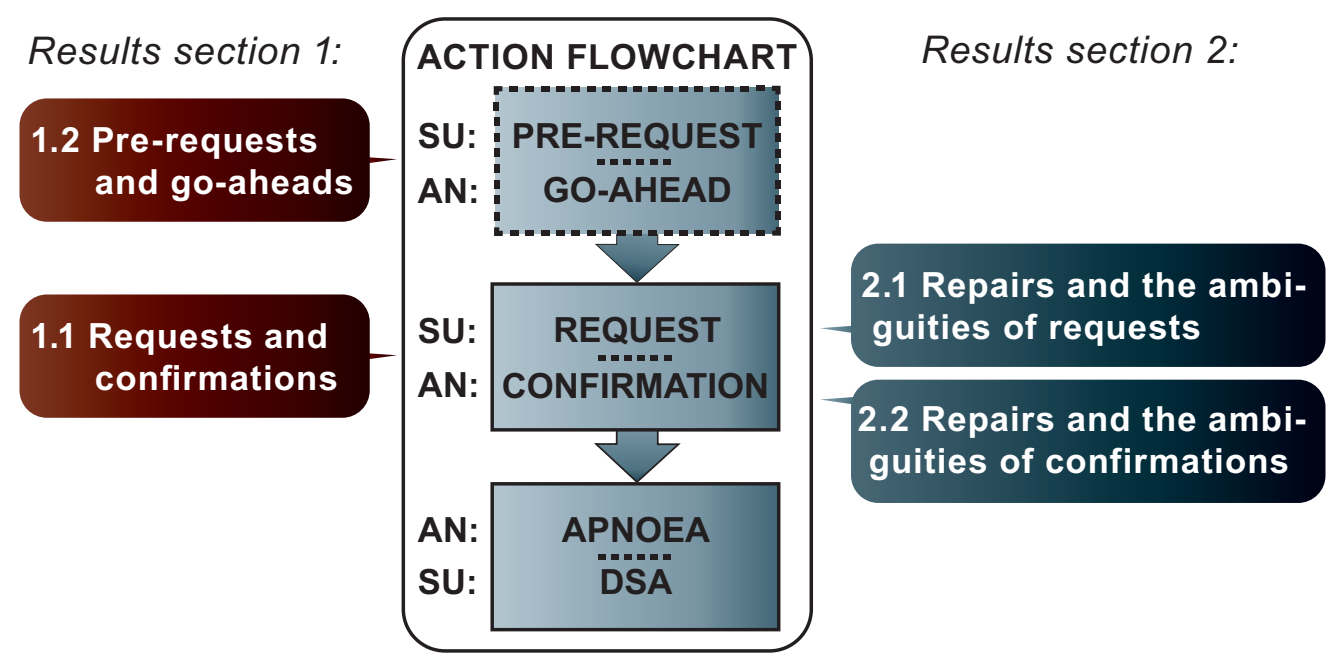

Figure 1 A simple communication model and the structure of the results. AN, anaesthetic nurse; DSA, digital subtraction angiography; SU, surgeon. 


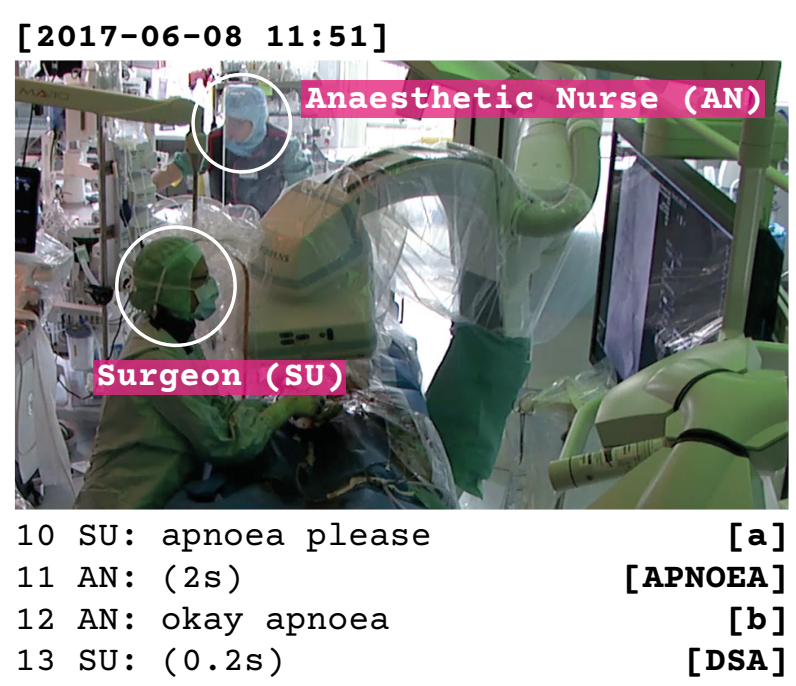

Figure 2 Fragment 1. AN, anaesthetic nurse; DSA, digital subtraction angiography; SU, surgeon.

variations were found among the communicative encounters. The figure also illustrates how individual sections of the results are organised. The first section is devoted to showing how this model could operate as a communication backbone that may fulfil certain organisational needs in the OR. Section 2 addresses specific communication problems that staff encountered and describes how these problems were resolved.

\section{Immediate requests and confirmations}

While it remains within the AN's domain to execute the apnoea, it is the operating surgeon (or radiology nurse $(\mathrm{RN})$ ) who decides when such an action should be taken. To bridge this communication gap, the surgeon issues an immediate request for apnoea. On hearing such a request, the AN will initiate the conditions needed to suspend the patient's respiration. However, before the surgeon can proceed with the imaging, an intermediate step is needed, that is, a confirmation that the apnoea state has been reached, which prompts the surgeon to proceed. Because of this relationship between the two steps, the actions of the immediate request and its confirmation comprise a form of interactional unit, what is also referred to as an adjacency pair. ${ }^{41}$

Fragment 1 (figure 2) begins with the surgeon (SU) calling for an action and expecting it to happen immediately. ${ }^{35}$ This kind of immediate request [a] is the most common way to communicate what is required and generally accomplishes the successful coordination of action between different team members. This communication design shares similarities with closed-loop communication: First, the initiator calls out a request, then the receiver grants the request by confirming it, which, in this setting, [b] also works as a marker for commencing the angiography [DSA]. An additional observation here is that the AN's response to the request is built through two separate items. The first is an acknowledgement token ('okay'), affirming that the nurse hears and understands the request. The second ('apnoea') confirms that the action has been or will be executed.

However, a complication arises here. Immediate requests are built on the premise that everyone in the OR is involved in the requester's project. The request must both be heard and understood if it is to be acted on immediately, but considering that the AN may not be monitoring the surgical activity closely at all times, the need arises for a routine that checks on the parties' availability whenever coordinated action is required. This is done by using the so-called pre-requests.

\section{Pre-requests and go-aheads}

The relation between the surgeon and the AN is different from that of, for instance, a surgeon and a scrub nurse. A scrub nurse may be assumed to be attentive to the unfolding of the surgical procedure and, to some extent, may anticipate upcoming needs in terms of instruments and the like. However, an AN has a separate ongoing project and, therefore, functions in and out of communication with the surgical team. ${ }^{42}$ Therefore, surgeons cannot always rely on having the AN's attention, which must be established and checked. This is when the communicative actions of pre-requests are useful.

Pre-requests fulfil several needs, setting up and projecting a longer communication sequence between different parties. The pre-request also may specify upcoming events and requirements in some detail. Most importantly, they offer the opportunity for the receiving party to either raise objections or give the go-ahead for the next part of the surgery. Thus, this (adjacency) pair may be characterised as pre-request and go-ahead, respectively.

Fragment 2 (figure 3) provides an illustration taken from an interactional sequence that displays all the components described above. In this sequence, the chief surgeon and AN coordinate their actions, and the analysis aims to point out how this coordination is accomplished in a turn-by-turn fashion. More specifically, the example illustrates how pre-requests and go-aheads support the surgeon and AN in successfully organising the upcoming request and the ensuing surgical actions.

The fragment begins as the surgeon (SU) calls out what is, in effect, a pre-request [a] to the AN. This is done by topicalising time twice and by naming the to-be-requested action ('apnoea'). The call-out is designed to project an upcoming activity to prepare the AN for this. The AN responds with a go-ahead [b] 'yes' and after a short pause also adds 'I'm awake'. This go-ahead from the AN, in turn, displays that the first turn is understood as a prerequest. It is framed as being part of the ongoing project through use of the metaphor of being 'awake', and no further action is taken at this time. A few seconds pass, after which the SU provides a request for direct action [c]. Again, time is topicalised. However, at this point, it is intended as an immediate request, with the expectation that the action will happen presently. The surgeon reiterates the requested action ('apnoea') and ends the utterance with a 'please', which, in conversational analysis 
[2017-06-08 09:52]

20 SU: then I'll soon ask for an

21 apnoea when it's time [a]

22 AN: YES (2.5s) I'm awake [b]

23 (11s)

24 SU: now then, APNOEA please [c]

25 AN: yeah

$26 \quad(4 \mathrm{~s})$

[d]

27 AN : apnoea

$28 \mathrm{SU}:(0.5 \mathrm{~s})$

[APNOEA]

[e]

[DSA]

Figure 3 Fragment 2. AN, anaesthetic nurse; DSA, digital subtraction angiography; SU, surgeon.

phrasings, 'extends the turn constructional unit beyond the name of the requested (action), and thus facilitates the request being fulfilled immediately upon the turn's completion' (Mandelbaum, p221). ${ }^{29}$ On this, the AN initiates a sequence of three events: First, an acknowledgement token [d] ('yeah') is provided, indicating that the request has been heard and understood. Next, the respirator is turned off [APNOEA]. Finally, a confirmation that the action has been carried out successfully is provided [e] ('apnoea'). The SU then responds to the confirmation by initiating the imaging process [DSA]

As this example illustrates, pre-requests commonly are used to verify a request's preconditions. In other words, a pre-request can be used to check for the other person's availability and to prepare that person for an upcoming immediate request. The presequence ensures that the involved parties are all observant and ready to hear and act on the command when it eventually is issued.

\section{Repairs and the ambiguity of requests}

The illustrations so far have shown how immediate requests and pre-requests are used to coordinate actions in the OR successfully. What will be shown in this section is how and why the surgical personnel encounter various difficulties in relation to requests for apnoea. As already indicated, pre-requests can become important devices in organising common projects. However, there are several instances in the collected data in which the members display difficulties in interpreting whether an utterance is designed to be a pre-request or an immediate request. Requests' ambiguities are clarified through conversational repairs. For ordinary conversations, such problems have been found to be exceedingly common, while also resolved regularly in due course. In high-risk settings, such as surgeries, it is important to keep any form of misunderstanding to a minimum. Therefore, the identification and mitigation of these repairs are important parts of ensuring care quality and safety.

If a request is made in the OR, the recipient of this request preferably should confirm that the request has been heard and understood by repeating the request (see fragments 1 and 2). However, when a problem exists in the way a request is formulated (or perceived), the recipient to (or the originator of) the request commonly initiates

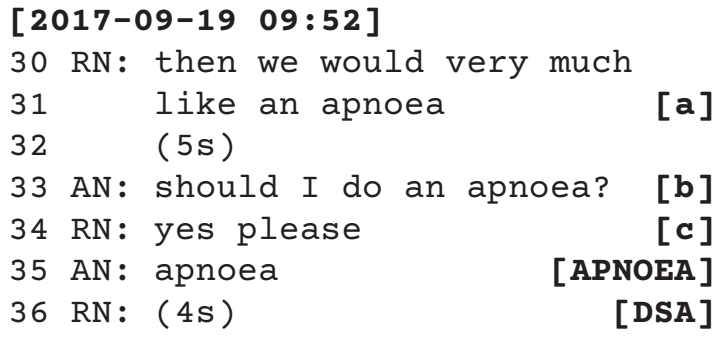

Figure 4 Fragment 3. AN, anaesthetic nurse; DSA, digital subtraction angiography; $\mathrm{RN}$, radiology nurse.

a repair to disambiguate the requested action. Fragment 3 illustrates such a repair sequence. In this situation, the $\mathrm{RN}$ and $\mathrm{AN}$ coordinate their actions.

The target utterance, and source of the problem, in fragment 3 (figure 4) is when the $\mathrm{RN}$ calls out 'Then we would very much like an apnoea' [a]. This utterance could be viewed as unclear in respect to what communicative action it is embodying. It could be interpreted as a pre-request that aims to prepare the AN for upcoming events, or it alternatively could be understood as an immediate request.

The AN treats this ambiguity as a problem-something that becomes interactionally manifested in two ways. First, there is silence or a pause. For several seconds, the AN does not respond. While such inaction is difficult to interpret analytically in terms of its meaning, a pause does provide space for, or invite, additional clarifications on behalf of the party who just spoke (in this case, the RN) ${ }^{43}$ When no such elucidation is offered voluntarily, the AN addresses the problem explicitly by asking for a clarification [b]. This so-called other-initiated repair is made in the form of a polar (yes or no) question that also includes a candidate interpretation of what the prior turn was aiming to do (a request for apnoea). So, rather than ask for a repetition of what was said, this turn is designed to target, specifically, the very problem that the AN is facing in disambiguating the previous turn. It shows that the AN was attentive and heard what was said, but that the form of the utterance made the action unclear (pre-request/immediate request). The RN confirms the AN's candidate interpretation with a 'yes please' [c], and the sequence proceeds without further difficulty.

What is illustrated with this sequence is that the $\mathrm{AN}$ is reluctant to begin any consequential action based on an ambiguous turn. Instead, a repair sequence is initiated to resolve the issue before taking any further action. This is clearly a form of safety management, and in this work, conversational repairs are crucial resources for establishing joint understanding between team members.

\section{Repairs and the ambiguity of confirmations}

As illustrated above, utterances made by RNs or surgeons can become difficult for ANs to interpret, but communication difficulties of this sort are not exclusive to one profession. The operators ( $\mathrm{SU} / \mathrm{RN}$ in this case) also may encounter problems when it comes to understanding 
[2017-11-28 10:34]

$40 \mathrm{RN}$ : can we have apnoea please? [a]

41 AN: apnoea (.) yes^

$42 \quad(0.4 \mathrm{~s})$

[b]

$43 \quad(0.3 \mathrm{~s})$

44 RN: apnoea now or?

$45 \mathrm{AN}$ : yes (.) apnoea

$46 \mathrm{RN}:(0.3 \mathrm{~s})$

[APNOEA]

[c]

[d]

[DSA]

Figure 5 Fragment 4. AN, anaesthetic nurse; DSA, digital subtraction angiography; $\mathrm{RN}$, radiology nurse.

the responses that they receive. For any communication project to function, it is not enough that one party makes their own contributions clear and unambiguous; they also must check on the receiving party's level of understanding.

Fragment 4 (figure 5) illustrates some of these problems when the RN calls out a request for apnoea [a]. The stress put on the two final words further emphasises the action as being a request and helps in making the communication clearer as it is done over some distance in the OR. The response [b] that the initial turn elicits is most interesting and the main target for this sequence. This response is constructed through repetition of the word 'apnoea' and, following a micropause, the affirmative 'yes'. What is observable in the video recordings is that the AN then turns the respirator off and executes the request [APNOEA]. It is not clear whether the RN perceives this action, but from what transpires, that seems unlikely.

Theoretically, this response turn [b] from the AN could be viewed as confirming the reception of information of the prior turn, thereby constituting an exemplary case for the 'check-back' part of the closed-loop communication model. ${ }^{15}$ However, this empirically is not a fully functional communication sequence. From the RN's perspective, after successfully hearing a request, what is expected next is possibly an acknowledgement token, but most definitely a confirmation. While these two parts do not have any fixed forms, predominant patterns are evident in the materials. The acknowledgement tokens overwhelmingly take the form of affirmatives, for example, 'yes', 'yup', 'yeah' and so on, but the confirmations tend to repeat the request's core action so as to specify the current state of 'apnoea'.

However, the initial response [b] in fragment 4 is alternating the order of the expressions commonly used in confirmation sequences. While this could be understood as a minor variation in the talk, it is evidently enough to trigger a repair sequence [c]. For the $\mathrm{RN}$, it is now unclear, through the response [b] received, what the AN made of the initial turn [a]. Did the AN hear it only as a pre-request? If so, the form 'apnoea (.) yes' would be a proper and understandable way to provide a go-ahead. But if it was heard as a request, the chosen format is a rare one and a cause of confusion. Thus, the RN initiates a repair by explicitly asking for clarification on the current state ('apnoea now or?').

The second response [d] confirms the candidate suggestion made by the $\mathrm{RN}$ through the affirmative 'yes' in combination with reiterating the keyword 'apnoea'. While the very same two words are the only ones uttered in both turns [ $b$ and $d]$, the latter turn now aligns with the more common format of acknowledgement token ('yes'), followed by a confirmation of the status ('apnoea'). This way, the switching of the word order dispels the confusion experienced by the $\mathrm{RN}$, and the imaging process is initiated.

\section{DISCUSSION}

This study has shown how conversational repairs are central in establishing a joint understanding and, therefore, how they can function as crucial resources in safety management. By explaining the interactional details of a few select examples, the study has exhibited some of the fundamental mechanisms through which most communication is structured by pointing to the procedural production of joint understanding and the coordination of actions in the OR.

A limitation of this work is that it only analysed 58 hours of interactions in a single setting. Based on this, one might argue that the showcased fragments amount to nothing more than anecdotal evidence. However, such an objection ignores the fact that the regularity and availability of the identified practices already have been established elsewhere. Through 50 years of rigorous analyses, with an ever-increasing corpus of corroborating studies, the field of conversation analysis has accumulated a rich understanding of how people-by way of these practices-come to understand each other in interactions. ${ }^{24} 41$ This specific analysis has added the knowledge that some of the same mechanisms are also at work in the studied setting.

This does not diminish the observations' value, as the consequences and implications for the medical setting are drastically different compared with most other settings. As a case in point, in the study, the stand-alone word apnoea was used in some instances to communicate a range of different actions, such as pre-requests and immediate requests, as well as go-aheads and confirmations. While these observations attest to the flexibility of language use, such versatility also opens up the possibility of unwanted vagueness. The presence of vague expressions during surgery cannot be viewed as being up to par with communication expectations nor are they fully compliant with safety-critical management. If the aim is to raise the quality of interprofessional communication during surgeries, these findings strongly suggest that one should devise an interactional framework that minimises problems with understanding.

By making the distinction between different types of requests explicit, ambiguities can be mitigated and some misunderstandings avoided. To enable this, different actions should be tied to clearer and more distinct forms of expression. One solution is to design key utterances so that they always include a temporal component, thereby specifying whether a request is wanted 'soon' (pre-) or 'now' 
(immediate). Furthermore, the responses are as central as the initial parts. Not only is some response necessary but the response also should be designed without ambiguity. Responses to advance warnings or calls for action explicitly must display what kind of communicative action they are replying to. If not, the initial party may find themselves wondering whether the action has been understood correctly, and a new round of clarification exchanges may be initiated. Such repetitions prolong operation time and increase interprofessional tensions due to frustration over ineffective communication. ${ }^{22}$

\section{CONCLUSION}

This general framework for understanding communication has much wider resonance, both in and beyond ORs, as communication problems can compromise patient safety.

Therefore, current models deployed to ensure more effective communication in medical settings ${ }^{13-16}$ should be complemented with the analytical resources for evaluating interactants' treatment of any inherent ambiguities in communicative exchanges.

To guide further research in this area, the following hypotheses are offered: the systematic use of pre-requests could improve situational awareness in interprofessional teams and increase their preparedness for upcoming actions. In addition, by implementing distinct forms of verbal expression, and thereby improving communication quality, some problems connected with noisy environments could be mitigated.

\section{Twitter Jonas Ivarsson @ivarsson_jonas}

Contributors Conception and design of the study: JI and MÅ; acquisition of data: Jl; analysis and/or interpretation of data: JI and MÅ; drafting the manuscript: Jl and MÅ; revising the manuscript critically for important intellectual content: JI and MÅ; approval of the version of the manuscript to be published: Jl and MÅ.

Funding The Swedish Research Council (grant No. 2015-03621) supported this research.

\section{Competing interests None declared.}

Patient and public involvement Patients and/or the public were not involved in the design, or conduct, or reporting, or dissemination plans of this research.

\section{Patient consent for publication Not required.}

Ethics approval Data collection commenced on approval by the Swedish Ethical Review Authority (Regionala etikprövningsnämnden i Göteborg; application id: 870-16) and after having acquired written informed consent from all parties participating in the study.

Provenance and peer review Not commissioned; externally peer reviewed.

Data availability statement № data are available. The data are video data which are not available for sharing due to confidentiality.

Open access This is an open access article distributed in accordance with the Creative Commons Attribution Non Commercial (CC BY-NC 4.0) license, which permits others to distribute, remix, adapt, build upon this work noncommercially, and license their derivative works on different terms, provided the original work is properly cited, appropriate credit is given, any changes made indicated, and the use is non-commercial. See: http://creativecommons.org/ licenses/by-nc/4.0/.

\section{ORCID iD}

Jonas Ivarsson http://orcid.org/0000-0003-3402-525X

\section{REFERENCES}

1 Cumin D, Skilton C, Weller J. Information transfer in multidisciplinary operating room teams: a simulation-based observational study. BMJ Qual Saf 2017;26:209-16.

2 Weldon SM, Korkiakangas T, Calzada J, et al. A surgical team simulation to improve teamwork and communication across two continents: ViSIOT proof-of-concept study. J Surg Educ 2019;76:1413-24.

3 Gillespie BM, Gwinner K, Chaboyer W, et al. Team communications in surgery - creating a culture of safety. $J$ Interprof Care 2013;27:387-93.

4 Greenberg CC, Regenbogen SE, Studdert DM, et al. Patterns of communication breakdowns resulting in injury to surgical patients. $J$ Am Coll Surg 2007;204:533-40.

5 Henaux P-L, Michinov E, Rochat J, et al. Relationships between expertise, crew Familiarity and surgical workflow disruptions: an observational study. World J Surg 2019;43:431-8.

6 Weldon S-M, Korkiakangas T, Bezemer J, et al. Communication in the operating theatre. Br J Surg 2013;100:1677-88.

7 Garosi E, Kalantari R, Zanjirani Farahani A, et al. Concerns about verbal communication in the operating room: a field study. Hum Factors 2019:001872081985827.

8 Gillespie BM, Harbeck E, Kang E, et al. Correlates of non-technical skills in surgery: a prospective study. BMJ Open 2017;7:e014480.

9 Mohammed A, Wu J, Biggs T, et al. Does use of a world Health organization obstetric safe surgery checklist improve communication between obstetricians and anaesthetists? A retrospective study of 389 caesarean sections. BJOG 2013;120:644-8.

10 Randell R, Honey S, Alvarado N, et al. Embedding robotic surgery into routine practice and impacts on communication and decision making: a review of the experience of surgical teams. Cogn Technol Work 2016;18:423-37.

11 Lingard L, Espin S, Whyte S, et al. Communication failures in the operating room: an observational classification of recurrent types and effects. Qual Saf Health Care 2004;13:330-4.

12 Firth-Cozens J. Why communication fails in the operating room. Qual Saf Health Care 2004;13:327.

13 Burke CS, Salas E, Wilson-Donnelly K, et al. How to turn a team of experts into an expert medical team: guidance from the aviation and military communities. Qual Saf Health Care 2004;13 Suppl $1: i 96-104$.

14 Salas E, Wilson KA, Murphy CE, et al. Communicating, coordinating, and cooperating when lives depend on it: tips for teamwork. Jt Comm J Qual Patient Saf 2008;34:333-41.

15 Härgestam M, Lindkvist M, Brulin C, et al. Communication in interdisciplinary teams: exploring closed-loop communication during in situ trauma team training. BMJ Open 2013;3:e003525.

16 Parush A, Kramer C, Foster-Hunt T, et al. Communication and team situation awareness in the or: implications for augmentative information display. J Biomed Inform 2011;44:477-85.

17 Shannon CE. A mathematical theory of communication. Bell System Technical Journal 1948;27:379-423.

18 Shannon CE, Weaver W. The mathematical theory of communication. Urbana: University of Illinois Press, 1949.

19 Rawls AW, Garfinkel H. Ethnomethodology and workplace studies. Organization Studies 2008;29:701-32.

20 Keller S, Tschan F, Semmer NK, et al. Noise in the operating room Distracts members of the surgical team. An observational study. World J Surg 2018;42:3880-7.

21 Keller S, Tschan F, Beldi G, et al. Noise peaks influence communication in the operating room. An observational study. Ergonomics 2016;59:1541-52.

22 Weldon S-M, Korkiakangas T, Bezemer J, et al. Music and communication in the operating theatre. $J$ Adv Nurs 2015;71:2763-74.

23 Hindmarsh J, Pilnick A. The Tacit order of teamwork: collaboration and embodied conduct in anesthesia. Sociol Q 2002;43:139-64.

24 Schegloff EA. Analyzing single episodes of interaction: an exercise in conversation analysis. Soc Psychol Q 1987;50:101-14.

25 Bezemer J, Cope A, Korkiakangas T, et al. Microanalysis of video from the operating room: an underused approach to patient safety research. BMJ Qual Saf 2017;26:583-7.

26 Bezemer J, Murtagh G, Cope A, et al. "Scissors, Please": The Practical Accomplishment of Surgical Work in the Operating Theater. Symb Interact 2011;34:398-414.

27 Mondada L. Working with video: how surgeons produce video records of their actions. Visual Studies 2003;18:58-73.

28 Mondada L. Instructions in the operating room: How the surgeon directs their assistant's hands. Discourse Studies 2014;16:131-61.

29 Mandelbaum J. How to do things with requests: requests at the family dinner table. In: Drew P, Couper-Kuhlen E, eds. Requesting 
in social interaction. Amsterdam, The Netherlands: John Benjamins, 2014: 215-41.

30 Schegloff EA, Jefferson G, Sacks $H$. The preference for selfcorrection in the organization of repair in conversation. Language 1977;53:361-82.

31 Schegloff EA. Repair after next turn: the last structurally provided defense of Intersubjectivity in conversation. American Journal of Sociology 1992;97:1295-345.

32 Sanchez Svensson M, Heath C, Luff P. Instrumental action: the timely exchange of implements during surgical operations. In: Bannon LJ, Wagner I, Gutwin C, et al, eds. Proceedings of the 10th European conference on computer supported Cooperative work. Limerick, Ireland: Springer, 2007: 41-60.

33 Koschmann T, LeBaron C, Goodwin C, et al. Formulating the triangle of doom. Gesture 2007;7:97-118.

34 Koschmann T, LeBaron C, Goodwin C, et al. "Can you see the cystic artery yet?" A simple matter of trust. J Pragmat 2011;43:521-41.

35 Mondada L. Requesting immediate action in the surgical operating room. In: Drew P, Couper-Kuhlen E, eds. Requesting in social interaction. Amsterdam, The Netherlands: John Benjamins, 2014: 269-302.
36 Hindmarsh J, Pilnick A. Knowing bodies at work: Embodiment and ephemeral teamwork in anaesthesia. Organization Studies 2007;28:1395-416.

37 Korkiakangas T, Weldon S-M, Bezemer J, et al. Nurse-surgeon object transfer: video analysis of communication and situation awareness in the operating theatre. Int J Nurs Stud 2014;51:1195-206.

38 Randell R, Greenhalgh J, Hindmarsh J, et al. How do team experience and relationships shape new divisions of labour in robot-assisted surgery? A realist investigation. Health 2019:136345931987411.

39 Landsberger HA. Hawthorne revisited: management and the worker, its critics, and developments in human relations in industry. Ithaca: New York State School of Industrial and Labor Relations, 1958.

40 Jefferson G. Transcription notation. In: Maxwell J, Heritage J, eds. Structures of social action : studies in conversation analysis. Cambridge: MA: Cambridge University Press;, 1984: 446.

41 Schegloff EA. Sequence organization in interaction. A primer in conversation analysis. Cambridge: Cambridge University Press, 2007.

42 Reason J. Safety in the operating theatre - Part 2: human error and organisational failure. Qual Saf Health Care 2005;14:56-60.

43 Restarts GC. Pauses and the achievement of a state of mutual gaze at turn-beginning. Sociological Inquiry 1980;50:272-302. 